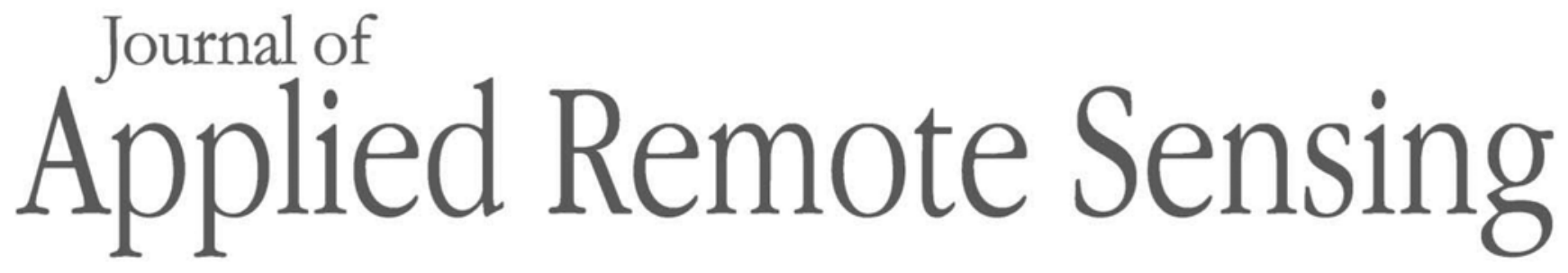

RemoteSensing.SPIEDigitalLibrary.org

\title{
Review of synthetic aperture radar frequency, polarization, and incidence angle data for mapping the inundated regions
}

Ramanuja Manavalan 


\title{
Review of synthetic aperture radar frequency, polarization, and incidence angle data for mapping the inundated regions
}

\author{
Ramanuja Manavalan* \\ Centre for Development of Advanced Computing, Bangalore, Karnataka, India
}

\begin{abstract}
The use and importance of synthetic aperture radar (SAR) data for flood area mapping studies have been proved beyond the doubts as SAR signals are able to penetrate the thick formation of clouds and are able to receive the reflected signals of surface objects even during extreme weather conditions. At the same time, the accuracies of an SAR image-based flood area mapping model has a direct relationship with the frequency of the source SAR signal, the polarization mode that has been used, and the incidence angle by which the disaster region has been sensed. In addition to this, while evolving SAR image-based flood area mapping models, it is a must to understand the response of the inundated regions of the different geographical regions, as well as the response of the same geographical region during different climatic and seasonal periods as the same object, produces different signatures in varying situations. As of this date, there is no single article that can synchronize such information, which is widely disseminated across various research publications. This article mainly focuses on gathering and reviewing such vital information as well as bringing out the details about the physical basis of the interaction of the radar signal with various water surfaces of different geographical conditions, the response of inundated regions under different frequency, polarization, and incidence angle. Such information is mainly used to understand the difficulties that arise when mapping the inundated regions using the SAR image. In the end, the significant observations of the literature reviews are highlighted, which is very useful for young researchers who are interested in building flood area application models using different sets of SAR data. (C) 2018 Society of Photo-Optical Instrumentation Engineers (SPIE) [DOI: 10.1117/1.JRS.12.021501]
\end{abstract}

Keywords: synthetic aperture radar; frequency; polarization; incidence angle; inundated regions.

Paper 170836V received Sep. 21, 2017; accepted for publication Apr. 24, 2018; published online May 15, 2018.

\section{Introduction}

Synthetic aperture radar (SAR) image-based application models have to be built on the basis of in-depth understanding of SAR signals response of object of interest as the response of the same object of interest from different geographical locations as well as during different climatic or seasonal variations producing varying image signatures. In addition to this, it is also important to understand the target objects response in different frequency, polarization, and incidence angle of the SAR sensor as the same object responds in a fluctuating way when the radar frequency, polarization, and incidence angle are different. ${ }^{1,2}$ Understanding the extent and quantum of such fluctuation is extremely significant, which enhances mainly the mapping accuracy of any SAR image-based application model. In line with this, this article primarily focused on SAR image-based flood area mapping theme and brings out the details about the physical basis of the interaction of the radar signal over the water bodies of different geographical locations, the response of the water bodies with different frequency, polarization, incidence angles as

*Address all correspondence to: Ramanuja Manavalan, E-mail: rmanavalan@cdac.in; saimanaindia@gmail.com 
well as the difficulties that arises while mapping the inundated pixels using different sets of SAR images. Hence, this article has a single point objective of "grouping and synchronizing the information content of SAR image-based flood area mapping studies specific to the response of SAR signals over different geographical regions, frequency, polarization, and incident angle." Research publications from various journals have been studied in detail and similar information pertaining to frequency, polarization, and incidence angle of the SAR signals has been grouped under separate sections. Initially, the role and response of SAR signals over the ocean surface, inland water bodies, flooded vegetation, and flooded urban regions is discussed in detail. Subsequent to this, the information pertaining to the role of radar polarization in mapping the inundated regions are brought out. In the end, the role of SAR incidence angle in mapping the inundated regions has been discussed. The concluding section highlights the list of inferences reached in this study. Overall, this article is significant to young researchers who are interested in developing new SAR image-based flood area mapping models with different sets of data.

\section{SAR Signal Scattering over Inundated Regions}

In satellite images, the flooded locations are visually identified based on the existing tonal contrast of the flooded as well as nonflooded regions. In an SAR image that has been captured during the flood situation, the tonal contrast can be seen between the wet and dry clusters of pixels, which in turn can be related with the varying backscattering range values $\left(\sigma^{0}\right)$ of the respective pixel groups of the image. Digitally, the inundated regions have much lower backscattering range than the surrounding nonflooded regions. ${ }^{3}$ Expansion of such tonal contrast regions that are inundated due to a recent flood is well appreciated when the before flood and after flood SAR image of the same region is compared. ${ }^{4-6}$ Any such variation in the tonal contrast and corresponding backscattering range is significant when a comparative assessment is made with the surrounding land mass of the disaster region. ${ }^{7}$ However, any such contrast mainly depends on the type of SAR signal scattering that happened over the study region, which ranges between specular reflections to diffuse scattering as the former one happens over the calm water surface and the later one happens over the water bodies, which has been severally agitated by the wind. In this regard, specific details about SAR signals response from the surface of the ocean, inland water bodies, flooded forest, flooded urban regions, as well as details about the associated signal scattering mechanism, happen over these regions and their corresponding signature impacts of the calibrated SAR image are brought out in the following sections.

\subsection{SAR Signal Response over the Ocean Surface}

Wind influenced waves are common phenomena over the ocean surfaces as well as nearby beach regions. Depending upon the intensity of the wind blowing, the backscattering range of the sea surface changes, which primarily depends on the wind speed and direction. During the calm wind blowing seasons, a regular pattern of the surface waves is observed synchronized to the direction of the wind flow. In such normal wind blowing seasons, the backscattering nature of the sea surface exhibits constant range, which can be related to the surface pattern of the ripples. ${ }^{8,9}$ This regular pattern of the sea surface is well observed in an SAR image when comparing the same SAR image, which is multilooked at 2:4 (azimuth 2; range 4) and 4:8 (azimuth 4; range 8 ). When there is a cyclonic turbulence, the coastal wave crosses the normal astronomical tide level and becomes a storm surge that inundates the nearby land regions. Such rough ocean leads to temporal irregular patterns over the sea surface and nearby beach regions cause very high backscattering due to the diffuse scattering of the SAR signals. ${ }^{10,11}$ Such irregular patterns are also observed in SAR images of large inland water bodies where wind blowing direction changes frequently or when such regions are influenced by monsoon rains. Ulaby et al. ${ }^{12}$ studied the relationship between the roughness natures of water surfaces with the incidence angle of an SAR sensor and reported the Bragg scattering, which is a unique scattering occurring over the slightly rough water surfaces with tiny capillary waves and short gravity waves at incidence angles beyond $30 \mathrm{deg}$. Later Hasselmann et al. ${ }^{13}$ and Hasselmann and Alpers ${ }^{14}$ attempted in bringing out the relationship between the wavelength of the periodically spaced surface patterns 
and the incidence angle of the SAR signal with the help of the Bragg equation. Raney ${ }^{15}$ observed that the Bragg scatterer patterns are oriented in such a way that the geometric structures aligned with the phase fronts of the SAR signal illumination and when they are spaced periodically in range direction the backscattering strongly increases through constructive inference at certain incidence angles. Lewis et al. ${ }^{16}$ observed enhanced brightness over the oceanic surface of the SAR image, which is in general equal to or higher than the land regions of the SAR image. Using L-band-airborne SAR data Minchew et al. followed polarimetric decomposition techniques mainly to derive the information about the differences between radar backscatter of oil slick regions and adjacent seawater. It has been observed that L-band backscatter from both oil and water consistently shows the backscatter mechanism to be Bragg backscatter from a tilted faceted surface with surface scattering being the dominant type of backscatter. At incidence angles less than $50 \mathrm{deg}$, oil shows a more dominant single scatterer than water albeit with significantly lower scattered power. Minchem et al. ${ }^{17}$ found that the behavior of oil and water differ as a function of incidence angle and volumetric concentration of oil.

\subsection{SAR Signal Response over the Inland Water Bodies}

The inland water bodies that have been captured by an SAR sensor during a calm wind period exhibit dark tonal contrast as the smooth surface of the water body acts as a specular reflector that directs the SAR signals away from the sensor direction thus produces dark tone in the SAR image. ${ }^{18-20}$ Hence, to map the boundaries of the inland water bodies, the energy interaction and reflection happening over the surrounding land regions of the water body has to be understood, which together produces varying tonal and textural contrast. According to the Rayleigh criterion, such land-water tonal contrast rises with increasing incidence angle. ${ }^{21-24}$ At the same time, higher incidence angle images are prone to the occurrences of more radar shadowing. ${ }^{13}$ This is most common in mountainous terrain as well as predominately seen in high-resolution SAR images. Such shadows are generally mixed with the signatures of smooth water surfaces and lead to errors of commission. In addition to this as Henderson observed in steep incidence angle images, due to abundance of layover pixels, the finer level terrain information is lost, which hinders in identifying the narrow water bodies such as the first-order drainage networks or stream networks of the steep slope regions. ${ }^{25}$ With reference to frequency of the SAR signals, the X-band SAR sensors ( 2.4 to $3.75 \mathrm{~cm}$ ) produces cloud shadows in the calibrated SAR image due to the attenuation of the short wavelength of the X-band signals. ${ }^{26,27}$ During flood-related disasters, the cloud formation over the disaster region is a parallel event. Hence, higher wavelength SAR data are preferred to map the inundated regions. The next level C-band SAR signals (3.75 to $7.5 \mathrm{~cm}$ ) has limitations such as low penetration, high-volume scattering as well as enhanced speckle effects that hinders in mapping the inundated pixels of densely vegetated regions as well as forest regions. ${ }^{28}$ The L-band SAR signals $(15$ to $30 \mathrm{~cm})$ exhibit more promising results in identifying the inundated status of agricultural regions than the C-band SAR image due to its long wavelength. ${ }^{29}$ The higher the frequency of SAR signals the higher penetration capability, hence the inundated status of a disaster region can be mapped well when using high-frequency SAR data.

\subsection{SAR Signal Response over Flooded Vegetation}

Interpretation of inundated vegetated regions of an SAR image requires the maximum level of understanding as SAR signals are prone to multiple scattering at various levels of vegetation as well as at subsurface or terrain level. These primarily include the scattering happening over the canopy level, from canopy to trunk level, tree stems to surface level, scattering from the rugged floor as well as from inundated water surface. The intensity of such scattering is heterogeneous in nature and varies from one image to another SAR image due to the varying nature of vegetation structures and closures. In addition to understanding such vegetation-related scattering natures, the sensor-related factors such as frequency, incidence angle, and polarization of the SAR signals are also needed to be given parallel importance so maximum possible information of the inundated status of vegetated regions can be extracted. The role and influence of all the above-mentioned parameters and related scattering mechanism happening over the inundated 
vegetation regions has already been widely studied by many researchers and the noted ones are Ormsby et al., Richards et al., Hess et al., Solomon, Wang et al., Henderson, Kasischke et al., Townsend and Walsh, Rao et al., Alsdorf et al., Townsend, Townsend and Foster, Costa, Lang et al., Hong et al., Voormansik et al., Pope et al., Saatchi et al.$^{30-51}$ In line with this, the following paragraph synchronizes and highlights the significant observations of relevant work performed by worldwide researchers.

Ormsby et al. discussed the list of issues related to the capability of using radar in detecting the inundation status of the vegetated regions. The magnitude at which the backscattering range increases due to flooding under vegetation is analyzed with the help of L-band SEASAT SAR, Lband shuttle SIR-A as well as with the airborne X-, C-, and L-band data. With reference to vegetation, Ormsby et al. observed that the L-band SAR data help to separate the deciduous or coniferous vegetation from the shorter, partially submerged grasses and shrubs. The Xand C-band radar data are useful when vegetation of the disaster region is relatively short in nature. With reference signal penetration and mapping the underlying inundated regions, it has been brought out that the X-band energy gets scattered at canopy level due to shorter wavelength hence there is less penetration and thus no enhancement from the water surface below. In the case of short grasslands, some of the C-band energy is reflected from the water surface and then subsequently rescattered back to the receiver producing a brighter return. Whereas the Lband radar able to produce a quantitative change in response between flooded and nonflooded conditions of the vegetated terrain ranging from 3 to $6 \mathrm{~dB}$ as this is able to penetrate deep into the trunks and reflect the signals from the below-standing water. ${ }^{30}$

Richards et al. have clearly defined the four kinds of SAR scattering mechanism, which together contributes to the return signals of flooded forests. Richards et al.'s illustration is shown in Fig. $1 .^{31}$ This includes scattering from the trunk to the forest surface, diffuse scattering from the rugged forest floor, volume scattering from the canopy, and volume to surface scattering happens at the trunk to surface level. Based on Ormsby et al. and Richards et al. studies, it can be firmly concluded that in any flooded SAR image, the combination of all types of the abovementioned scattering leads to a composite backscattering value over the forested region, which is higher than the nonflooded conditions. ${ }^{30,31}$ The same has been confirmed subsequently by Wang et al., Kasischke et al., Townsend, and Hong et al. ${ }^{37,39,43,48}$

In addition to the above studies, Hess et al., Townsend and Foster, and Lang et al. have published comprehensive reviews of the interaction of various radar systems with a wide range of vegetation types. ${ }^{32-35,45,47}$ All such studies insist on using the longer wavelength SAR as the longer the wavelength the higher is the capability of the signal to penetrate the vegetation canopy. This is particularly significant when the wavelength is substantially longer than the leaf size. ${ }^{37,50}$ Lang et al. found that the increase in the canopy foliage leaf-area index reduces the transmissivity of the crown layer and thus diminishes the amount of microwave energy reaching the forest floor. ${ }^{47}$ In general, over such flooded forest regions, high classification accuracy is obtained when using the high wavelength SAR signals during the leaf-off conditions. ${ }^{45}$ In this

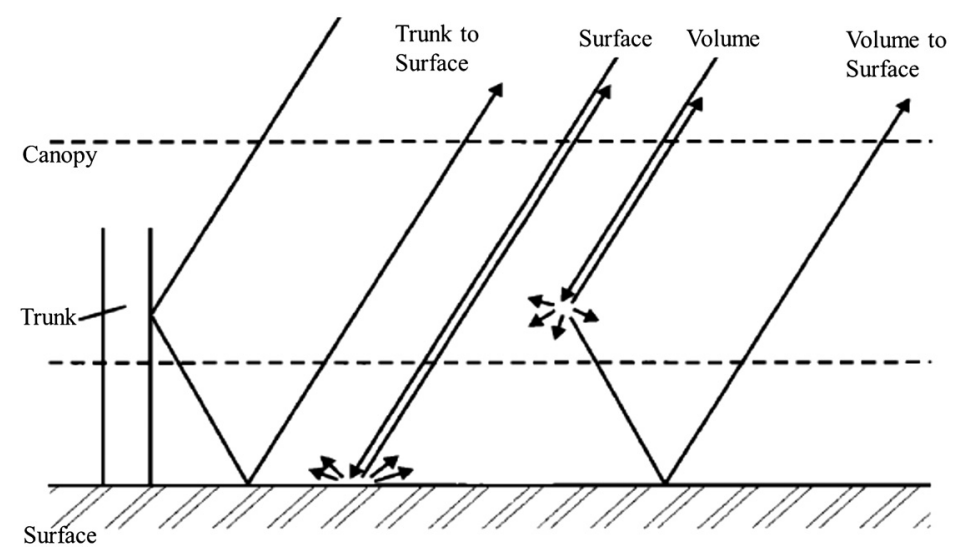

Fig. 1 Four components of backscatter from forest region, Richards et al. ${ }^{31}$ 
regard, the L-band SAR sensors have proven to be more effective in mapping the flooded forest. $^{30,31,40,52}$

In case of using the C-band SAR data, publications from Townsend and Walsh, Rao et al., Townsend, Costa, and Lang et al. prove that C-band SAR data still act as a valuable tool in mapping the flood beneath the forest regions where canopy is sparse and short. ${ }^{40,41,43,44,46,47}$ Horritt et al. ${ }^{19}$ observed enhanced backscatter of marshland environment in the C-band image rather than in L-band as the C-band signal able to penetrate the sparse canopy cover as well as able to interact with the water surface of the lower part of the flooded vegetative region. Over a lake environment, Alsdorf et al. ${ }^{42}$ reported increase in the C-band backscatter value due to the presence of floating aquatic macrophytes as well as budding shrubs.

While using X-band SAR data, Henderson, Solomon, and Ormsby et al. ${ }^{30,36,38}$ observed the prominent occurrence of double-bounce returns from the edges of the sparse flooded forest trees where the penetration of X-band signals is not an issue. Ormsby et al. ${ }^{30}$ have brought out the relationship of SAR wavelength over flooded grasses, herbaceous, and timber vegetation, which clearly exhibits the enhanced backscattering of X-and C-band SAR data over the marshland regions. Voormansik et al. ${ }^{49}$ have used high-resolution TerraSAR-X SAR images and found that TerraSAR-X produced higher average backscatter value of 3.2, 4, and $6.2 \mathrm{~dB}$, respectively, over mixed flooded forest areas, flooded coniferous forests regions, and flooded deciduous regions. These results were also compared with 12.5-m spatial resolution L-band ALOS-1 PALSAR and 150-m spatial resolution C-band ENVISAT ASAR images of the same flooding event and confirmed that L-band ALOS-1 PALSAR is superior for detecting floods under dense canopy.

The studies related to using C-, X-, and L-band data over the inundated vegetated regions bring out the fact that over the sparse forest cover region with thin branches and small diameter trunks, brighter backscattering effects occur even with short wavelength signals. The need of Lband SAR is unavoidable over the densely forested regions. In practical situations, temporal monitoring of any regional scale flood events of forested terrain has to make use of the available SAR sensors, which passes through the respective disaster region. Hence, understanding the response of different wavelength SAR signals over the flooded forest region is required to produce accurate mapping results.

\subsection{SAR Signal Response over Flooded Urban Region}

In the 1990's, Giacomelli et al. ${ }^{52}$ and Oberstadler et al. ${ }^{53}$ used ERS-1 SAR data to map the inundated status of settlements along with the land use and land cover classes of the disaster region. Due to its coarse resolution of ERS-1 SAR images, Oberstadler et al. found difficulties in separating the flooded settlement from nonflooded settlement regions. ${ }^{53}$ Later in the 2000's, using an automatic texture-based maximum likelihood classifier algorithm, Solbø and Solheim $^{24}$ attempted in mapping the urban flood area using ERS-1, VV polarization SAR image, and brought out that in the urban areas it is nearly impossible to do a practical mapping of inundated regions due to high concentration of strong SAR scatter signature as this enhances the backscattering values of the respective disaster locations.

Mason et al. ${ }^{54-57}$ made remarkable contributions in analyzing the inundated regions of the urban area using high-resolution TeraSAR-X data. Mason et al. have brought out the possible combinations of SAR backscattering effects of urban streets as shown in Fig. 2, which schematically shows two buildings separated by a flooded street. The dihedral and trihedral reflection from the buildings as well as the presence of metal surfaces lead to enhanced backscatter over the urban part of the image. Moreover, the double-bounce effect between roads and walls of the urban structure along with the radar-specific illumination phenomena over the urban region adversely affect the appearance and ability to detect flooding. In addition to this, considerable urban areas might not be visible due to shadowing (CD) and layover (AB) effects of SAR. The only possibility to observe an inundated region is between $\mathrm{B}$ and $\mathrm{C}$ due to specular reflection of SAR signals as shown at point Y of Fig. $2 .{ }^{54}$ Hence, while using high-resolution SAR, when the distance between $\mathrm{B}$ and $\mathrm{C}$ increases, there is a possibility to map the flooded pixels of urban SAR image. However, when the pixels from nonflooded roads and other smooth manmade surfaces are associated with these regions, it is hard to differentiate and separate these smooth surfaces as 


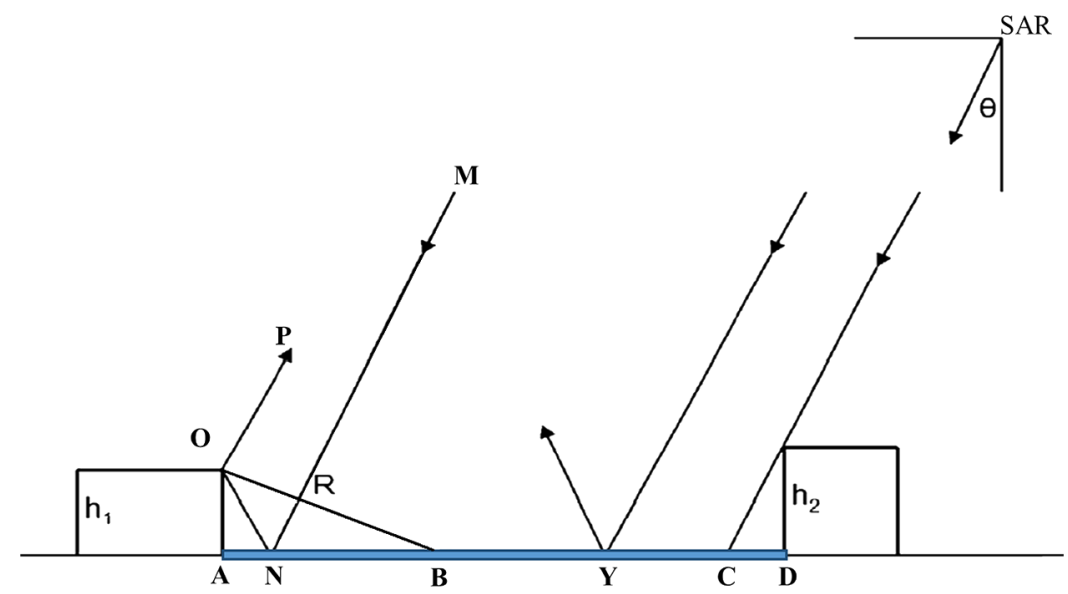

Fig. 2 Layover $(A B)$ and shadow $(C D)$ regions in a flooded urban street $(A D)$ between adjacent buildings of height h1 and h2. $\theta$ is the incidence angle, Mason et al.

these regions exhibit specular reflection. Overall, assessment of flooded urban regions using an SAR image is complicated due to multiple backscattering effects that are mainly dominated by the corner reflection of urban buildings and other concrete infrastructures. Later, Mason et al. designed an algorithm for SAR image-based urban inundation mapping, which requires inputs from high-resolution light detection and ranging (LiDAR) data and input from DLR TerraSAR-X simulator to generate the maps of shadow and layover regions of the urban area. Initially, the input SAR scene is logically divided into rural and urban areas and resampled to match the resolution of LiDAR DSM data. Subsequent to this, multistage object segmentation techniques have been used to separate the image water bodies, high land objects, and nonwater objects. In case of the rural part of the image, a threshold has been defined based on the context of the object with the adjacent flooded area, and objects falling to more than this threshold has been classified as flooded. In case of the urban part of the image, seed pixels are identified over the low backscattering regions as training data mainly to classify the pixels into the urban water and nonwater classes. Mason et al. ${ }^{55,56}$ approach involves first detecting flooding in the rural areas and then detecting it in the urban areas using an algorithm guided by the rural flood extent. Hence, the method may not produce promising results in a situation or SAR image where the flood is totally confined within the urban region. Subsequent to this, Mason et al. ${ }^{57}$ enhanced the same flood detection algorithm based on the GO-GO double scattering method of Franceshetti et al. ${ }^{58}$ This approach assumes that the regions of urban flooding detected by their strong double scattering could act as additional clues that could be combined with the already detected flooded urban regions that were not in radar shadow or layover. ${ }^{57}$ For all these urban inundation studies, Manson et al. used the aerial photograph of during flood season, postflood SAR scene of the same SAR sensor of the same incident angle, and LiDAR DSM of the disaster area in enhancing the accuracy of the classification as well as in validating the obtained results. ${ }^{55-57}$

Giustarini et al. followed a hybrid method of approach, combining calibration of gamma distribution function, radiometric thresholding, region growing, and change detection techniques to map the inundated pixels of during flood and postflood SAR images. Keeping the postflood image as a reference image, the permanent water bodies were extracted and with reference to this, the flood extent of the during flood image is compared to mark the inundated pixels. The results were validated with the help of 0.2 -m resolution aerial photographs and found $82 \%$ accuracy is possible through this approach. ${ }^{59}$

Pradhan et al. used the TerraSAR-X data of during flood season along with the Landsat optical data of after a flood event in mapping the urban flooded regions. After the initial stage of preprocessing, both these images were segmented as per rule-based classification approach of Taguchi technique. From TerraSAR-X, only flooded and nonflooded pixels are classified. Using Landsat image, vegetation, water, and urban objects are classified. Subsequently, the water bodies extracted from the SAR image and optical image were subtracted to identify the inundated pixels. ${ }^{60}$ 


\section{Role of Radar Polarization in Mapping the Inundated Regions}

In SAR image-based flood area mapping application, selecting the right choice of the polarization image has to be given maximum importance as this plays a significant role in classifying the inundated regions with maximum possible accuracy. Hess et al. analyzed temporal SIR-C data of the Amazon river flood region and experienced both C-band and L-band co- and crosspolarization data and observed that $\mathrm{HH}$ polarization was most useful for distinguishing flooded from nonflooded vegetation and crosspolarized L-band data provided the best separation between woody and nonwoody vegetation. To be specific, Hess et al. ${ }^{61}$ observed the best separation of macrophyte versus pasture in C-band $\mathrm{HH}$ polarization data and flooded versus nonflooded forest in L-band $\mathrm{HH}$ polarization data. The same observations have been reconfirmed by Hess and Melack, by analyzing the inundation status happening over a creek environment. ${ }^{35}$

Specific to SAR polarization and flood area mapping theme, studies of Henry et al. ${ }^{62,63}$ are more informative as in these articles much emphasis have been given in identifying the most suitable polarization data by analyzing the backscattering behavior of water bodies against the different polarization SAR signals. The Elbe river flooding of the year 2002 has been analyzed using the $\mathrm{HH}$ and HV polarization data of ENVISAT ASAR and VV polarization data of the ERS-2 satellite. These data were acquired on the same day within half an hour temporal period. Figure 3 of Ref. 62 shows the basic statistics of $\mathrm{HH}, \mathrm{HV}$, and VV polarization images and its analysis exhibits that $\mathrm{HH}$ histogram is much wider and exhibits higher radiometric dynamics than the other two polarization images. The wide histogram of the $\mathrm{HH}$ polarization image helps for the better discrimination of thematic classes including possible differentiation of identifying the open water from recently inundated areas, which mostly requires high-resolution SAR images. ${ }^{63}$ The radiometric profiles of Fig. 4 of Ref. 63 gives clear indication that that HH signal is less backscattered than HV or VV polarization images. Other noted studies focused on SAR backscattering behavior of water bodies are Refs. 37, 44, and 64. Both Wang et al. and Townsend observed that the ratio of backscatter from flooded forest to that from a nonflooded forest is higher at $\mathrm{HH}$ polarization than at VV polarization. ${ }^{37,44}$ Leckie and Ranson study reveals that backscattering is generally very weak in crosspolarization data. ${ }^{64}$

Studies related to using multipolarized SAR data for analyzing the object of interest also exhibited inclination or shows preference in using the like-polarization data when it is available. ${ }^{65-67}$ In line with this, the other noted flood related studies are from Refs. 3, 23, 63, and 68. All these floods-related studies observed that $\mathrm{HH}$ polarization is able to well discriminate between water and other surrounding land cover classes as it offers the best radiometric dynamic range. This is due to the low scattering of the horizontal component of the signal from the open-water surface. Martinis and Rieke observed that over the smooth water surfaces, like

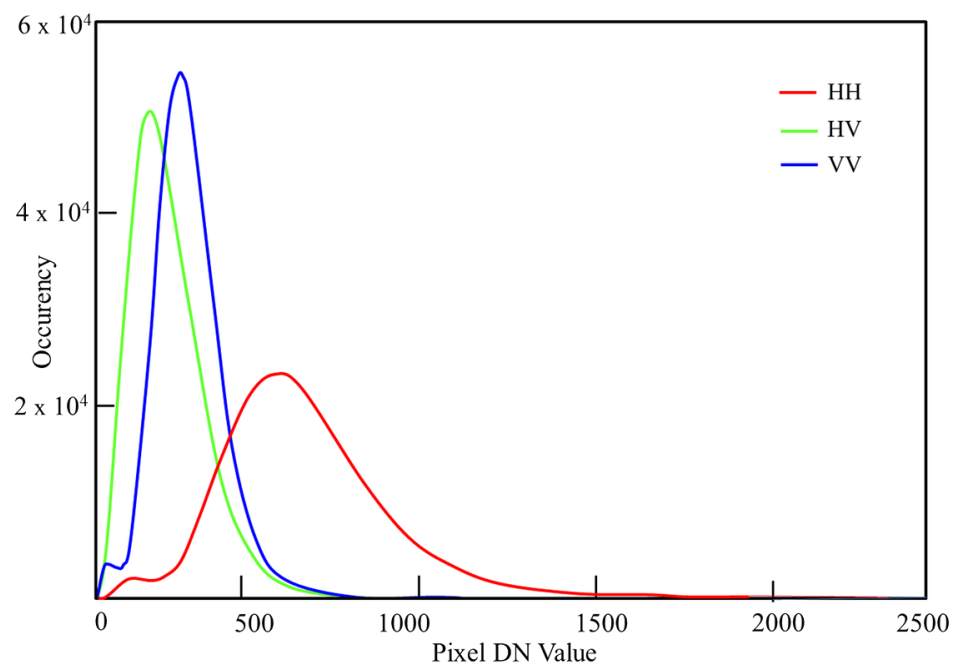

Fig. 3 Histograms of ENVISAT ASAR HH and HV polarization images with equivalent number of looks (ENL) 1.9 and ERS-2 VV polarization image with ENL of 3. Both ENVISAT and ERS-2 images were acquired on August 19, 2002, Henry et al. 


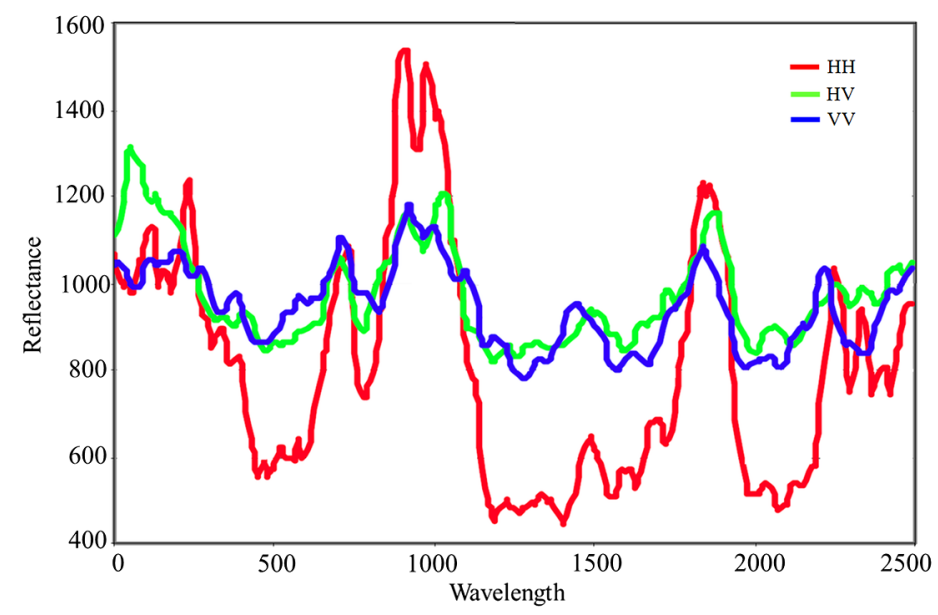

Fig. 4 Radiometric profile of $\mathrm{HH}, \mathrm{HV}$, and VV polarization data of ENVISAT ASAR of Elbe River flooding, Henry et al.

polarization images able to give better class separability than the crosspolarization images. ${ }^{3}$ Studies by Horritt et al., Nghiem et al., and Henry et al. suggest using multipolarization data for flood area mapping. ${ }^{19,63,69}$ Horritt et al. experienced that radar system with multipolarization modes can provide more information of the inundated status of the densely vegetated area than single-polarization radars. ${ }^{19}$ In line with this, studies by Nghiem et al. and Henry et al. suggest that the accuracy of the flood area mapping may be enhanced by combining the information pertaining to the backscattering variation of different polarization images. ${ }^{63,69}$

The in-depth study of the abovementioned literature brings out the advantage of using $\mathrm{HH}$ polarization data for flood area mapping due to its reduced backscattering sensitivity to the water surface as well as high radiometric dynamic range. However, during areal-time global scenario getting the HH polarization data may not be always possible. In such a situation, the task of mapping the inundated pixels has to be done with the available multimode, multipolarization SAR data. In line with this Manavalan et al. have analyzed SAR data of $\mathrm{HH}, \mathrm{VH}$, and VV polarization data of the same as well as different geographical regions. ${ }^{29,70}$ A comparative flood area assessment of the same flood event covering the same geographical region has been analyzed using C-band ENVISAT ASAR of VH and VV polarization and L-band $\mathrm{HH}$ polarization data of ALOS-1 PALSAR satellite. ${ }^{29}$ For the remote location, the available Cband ENVISAT HH polarization data have been analyzed. ${ }^{70}$ These analyses suggest that in the absence of a $\mathrm{HH}$ polarization image, the crosspolarization images of $\mathrm{VH}$ and $\mathrm{HV}$ data are the preferred choice of data for flood area mapping application. ${ }^{68}$ The VV polarization data due to their sensitivity over the rough water surface as well as enhanced volume scattering of vegetated flooded regions seem to provide less information for any flood-related studies.

\section{Role of SAR Incidence Angle in Mapping the Inundated Regions}

In flood area mapping applications, the incidence angle of the sensor at which the terrain information is captured plays a significant role as SAR signal response from steep to narrow incidence angle has considerable impact in the radiometric and backscattering range of the SAR image. Few publications notably by Ormsby et al. and Imhoff et al. state that variations in the incidence angle do not affect the detection of the flood areas. ${ }^{30,71}$ However, later studies confirm that the incidence angle factor is much more significant when the region is covered with sparse to dense forest covers. Studies by Richards et al., Hess et al., Wang et al., Wang and Imhoff, and Bourgeau-Chavez et al. ${ }^{31,32,37,72,73}$ indicate that the steeper small incidence angles are preferable to distinguish the flooded forest from nonflooded forest regions. The signals of steep incidence angles have more penetration capabilities through the canopy cover due to its shortest travel path, which in turn supports increased transmissivity at the crown level as well as permits more energy 
interaction at ground-trunk level. In contrast, shallow incidence angle signals interact more at the canopy level, which in turn increase the volume scattering.

Townsend and Foster analyzed 32 RADARSAT-1 SAR scenes of multiple incidence angles ranging from 10 deg to 46 deg collected between 1996 and 2001 over the Roanoke River floodplain, North Carolina, to map the flood beneath the forest canopies. ${ }^{45}$ It has been observed that the SAR images collected during the leaf-off period produced more accurate results of greater than $95 \%$ accuracy regardless of incidence angle. It is also observed that images acquired at shallow incidence angles ranging from 41 deg to 46 deg S6 mode of RADARSAT- 1 are affected by speckle. The images acquired at very steep incidence angles ranging from $10 \mathrm{deg}$ to $23 \mathrm{deg}$ shows a considerable amount of geometric feature displacement hence they could not be used for mapping applications. Sokol et al. analyzed HH, HV, and VV polarization images of SIR-C data of varying incidence angle of $39 \mathrm{deg}, 46 \mathrm{deg}$, and $58 \mathrm{deg}$ and found that the differences between flooded forest and nonflooded forest were visually detectable in the HH image having the low incidence angle of $39 \mathrm{deg} .{ }^{74}$ While analyzing the other two high incidence angle images, it has been found that the contrast between water and vegetated surfaces increased due to the brighter appearance of tree surface but the differences between flooded and nonflooded forests were less evident in the HH polarization image and not detectable in the HV. Solbø and Solheim used the ERS, VV image for flood area mapping and observed that the contrast between water and land decreased with decreasing incidence angle at the times of increasing wind speed. ${ }^{24} \mathrm{Li}$ et al. ${ }^{75}$ studied the effect of different incidence angles and related radar backscattering effect over various land cover types. Through this study, it has been observed that while using the C-band, $\mathrm{HH}$ polarization RADARSAT-1 data, the mean backscatter return of each land cover type decreases as the incidence angle increases. With reference to understanding the influence of SAR incidence angle in identifying the inundated regions, Lang et al. observations are more significant as this article relates the inundated status of leaf-off and leaf-on seasons of different forest cover regions at a varying incidence angle of RADARSAT- $1 \mathrm{HH}$ polarization images ranging from $23.5 \mathrm{deg}$ to $47 \mathrm{deg}$. Lang et al. ${ }^{47}$ observed decrease in the backscattering value at increased incidence angle images and observed the best discrimination of flooded and nonflooded forests while using data collected at moderate incidence angles of $27.5 \mathrm{deg}$ and $33.5 \mathrm{deg}$.

Overall, the role of incidence angle in mapping the inundated regions is not captured in any single article hence significant information from various studies are brought out in this section. From these studies, it can be stated that the ability to detect the inundation of flooded forest cover regions decreases with increasing incidence angle as when incidence angle increases, more direct interaction occurs at canopy level, which in turn increases the volume scattering. Hence, for the flood area mapping, the steep to moderate incidence angle images are preferable of which the steep incidence angle images are preferable to map the inundated regions of dense vegetatation, as well as forest cover regions and moderate incidence angles images, are preferable to map the sparsely vegetated region. Moreover, the steep and moderate incidence angle SAR images acquired during the leaf off period will be able to capture more information about the inundation status of the disaster region than leaf-on period images.

\section{Conclusion}

In this article, much emphasis has been given to understand the response of the SAR signals of inundated regions under different frequency, polarization and incidence angles of the SAR sensor. To this end, users understanding about identifying a suitable SAR image from the available sets of data is improved. In this regard, seventy plus research publications, which fall between the years 1981 and 2017, have been reviewed before reaching the following conclusions. It is evident for any SAR image-based flood area mapping applications; data from a high-frequency SAR sensor is the most preferable choice. ${ }^{29}$ With the available X-, C-, and L-band spaceborne SAR sensors, the flood area mapping results that have been derived using L-band SAR is exhibiting promising results as L-band SAR is able to map more inundated regions than X-or C-band SAR data. The deeper penetration capabilities of L-band SAR help better discrimination of the ground features as well as in mapping additional inundated regions that cannot be observed in Cor X-band SAR data. The short wavelength X-band SAR signals are prone to multiple scattering 
at canopy level hence will not be useful to map the inundated status of densely vegetated or over the forest regions, also the X-band SAR sensors produce cloud shadows due to the attenuation of short wavelength signals. ${ }^{26,27}$ The C-band SAR data exhibit encouraging results over the regions where vegetation cover is sparse and used when the availability of high-frequency SAR sensor coverage is limited. ${ }^{28}$

With reference to identifying suitable SAR polarization data for the flood area mapping application, it has been observed that the flooded areas would be easier to identify with like-polarized data rather than crosspolarized data. ${ }^{65-67}$ Among polarization data, it has been widely accepted that $\mathrm{HH}$ polarization is preferred due to its high radiometric dynamic, less backscattering nature, and reduced sensitivity to water surface. ${ }^{3,23,29,62,63,68}$ For flood area mapping application, VV polarization SAR data are generally avoided due to its known nature for enhanced volume scattering, high speckles presence as well as lack of canopy penetration. Studies that use VH and HV polarization data exhibit better results than VV polarization data due to the reduced nature of scattering and speckles. ${ }^{68}$ Hence, in the absence of HH polarization, data from $\mathrm{VH}$ and $\mathrm{HV}$ polarization are other preferable choices for flood area mapping application. ${ }^{29,68,70}$

With reference to the role of the incidence angle of SAR sensor in the flood area mapping theme, it has been observed that over a vast open area increase in the incidence angle enhances ground and open-water boundaries because of stronger specular reflection of smooth water. However, such images produce an opposite effect over the dense vegetated or forest cover regions where the steep incidence angle images are preferable as signals from steep incidence angle can penetrate more into the canopy as the signal has short passage. ${ }^{31,32,37,72,73}$ In forested regions, it has been observed that the contrast between flooded and nonflooded forest decrease with increasing incidence angles since at large angles the radar interacts more with the forest canopy than with the underlying objects. In many flood area mapping studies, the moderate incidence angle SAR images ranging from $27 \mathrm{deg}$ to $33 \mathrm{deg}$ are preferable choice. ${ }^{47}$

In addition to the above frequency, polarization, and incidence angle-related observations, the other significant observations are highlighted in the following points, which need to be taken care of by the young researcher who is interested in developing new SAR image-based flood area mapping models.

- SAR signals over a flat water body produce specular reflection, which is directly related to the lowest backscattering range of the respective image. This has been carefully addressed and mapped when developing a SAR image-based flood area mapping model as similar backscattering value is very much possible over the shadow regions as well as the far swath regions, which are away from the image center.

- Only the SAR images that have been captured during the calm wind flow period exhibits specular signatures. In real-time disaster situations, specular reflection of the inundated region is not always common as this is been influenced by wind, turbidity level of water, ripples, forest cover of the region, layover, shadow, incidence angle of the sensor, polarization of the radar signal, etc. Hence, processing of SAR images that have been acquired during the disaster period requires the deep understanding of SAR signal response over different topography, influence of polarization, incidence angle, etc. and the respective details have been discussed in detail in previous sections of this article.

- Over the regional scale water bodies, the action of wind creates successive ripples that scatter the incidence radar signals. In general, there will be a pattern of ripples observed over the ocean surface and nearby inland creek environment. But a similar homogeneous pattern is uncommon over the inland water bodies, which mostly exhibits irregular patterns. Over such ripples dominated surface regions of the SAR image, enhanced backscattering values are observed.

- The enhanced backscattering observed over a flooded forest region denotes the increased scattering of SAR signals happening over various levels of forest cover and subsurface terrain. The signals are scattered at canopy level, at trunks, stems level, and finally at the layer of accumulated inundated water, which occurs beneath the forest cover. The return signal from the flooded forest surface once again scattered at various levels before it reaches the sensor. Hence, the backscattering coefficient measured over a flooded forest 
region or flooded vegetated region is higher than the backscattering coefficient that has been measured during dry conditions.

- In general, while analyzing the SAR images of leaf-on and leaf-off period of the same region, the leaf-off forest is expected to yield at least $1 \mathrm{~dB}$ lower enhancement of backscattering value than leaf-on forests due to the absence of canopy level leaf scattering. This may not be true when the forest cover is very sparse.

- In case of flooded vegetated regions, the densely vegetated cover produces more complex radar response, which depends on the vegetation type and its height, as well as the level of standing water accumulated beneath the vegetation. This can be addressed with the help of using high-frequency SAR as well as evolving land use, land cover-based flood area mapping models.

- Urban regions of the SAR image is known for very high backscattering values due to the corner reflection of input SAR signals from the concrete urban buildings as well as surrounding urban infrastructure. Such radar response does not support in mapping the actual inundated regions of urban regions. Hence, with reference to a real-time disaster scenario, flood area mapping of urban regions is a challenging task, which is mostly addressed by domain experts with the help of a LiDAR height map of the urban area.

- With reference to identifying suitable frequency, polarization and incidence angle data that have been discussed in this article, it can be firmly concluded that high-frequency such as L-band and above, a HH polarization SAR image of moderate incidence angle ranging from $27 \mathrm{deg}$ to $33 \mathrm{deg}$ is the most preferred choice for any flood area mapping studies. In absence of $\mathrm{HH}$ polarization, the $\mathrm{VH}$ polarization data can be used. The C-band $\mathrm{HH}$ polarization data can be used to map the inundated regions where the canopy cover is sparse and short.

\section{Acknowledgments}

The author acknowledges the encouragement given by Professor Y.S. Rao and Professor B. Krishna Mohan of CSRE, IIT-Bombay, India, as well as support extended by Ms. Supriya Pal, Mrs. Mangala, and Shri Ganga Prasad of C-DAC, Bangalore, India, in accomplishing this work.

\section{References}

1. A. Moreira et al., "A tutorial on synthetic aperture radar," IEEE Geosci. Remote Sens. Mag. 1(1), 6-43 (2013).

2. Canada Centre for Remote Sensing, "Fundamentals of remote sensing, remote sensing tutorial," Chapter 3, Microwave Remote Sensing, 2016, http://www.nrcan.gc.ca/earthsciences/geomatics/satellite-imagery-air-photos/satellite-imagery-products/educationalresources/9391 (17 August 2016).

3. S. Martinis and C. Rieke, "Backscatter analysis using multi-temporal and multi-frequency SAR data in the context of flood mapping at River Saale, Germany," Remote Sens. 7, 7732 7752 (2015).

4. S. Schlaffer et al., "Flood detection from multi-temporal SAR data using harmonic analysis and change detection," Int. J. Appl. Earth Obs. Geoinf. 38, 15-24 (2015).

5. M. A. Clement, C. G. Kilsby, and P. Moore, "Multi-temporal synthetic aperture radar flood mapping using change detection," J. Flood Risk Manage. 1-15 (2017).

6. A. Rémi and Y. Hervé, "Change detection analysis dedicated to flood monitoring using ENVISAT Wide Swath mode data," in Envisat Symp., ESA SP-636 (2007).

7. M. J. Lee, "Detecting flooded locations using SAR data and assessment of post-flooded condition," AASCIT Commun. 2(4), 99-103 (2015).

8. D. J. Schwab, R. A. Shuchman, and P. C. Liu, "Wind wave directions determined from synthetic aperture radar imagery and from a tower in Lake Michigan," J. Geophys. Res. C Oceans 86(C3), 2059-2064 (1981). 
Manavalan: Review of synthetic aperture radar frequency, polarization, and incidence angle...

9. B. Chapron, H. Johnsen, and R. Garello, "Wave and wind retrieval from SAR images of the ocean," Ann. Telecommun. 56(11-12), 682-699 (2001).

10. J. A. Zhang and X. Li, "Tropical cyclone multiscale wind features from spaceborne synthetic aperture radar," Chapter 2 in Hurricane Monitoring with Spaceborne Synthetic Aperture Radar, X. Li, Ed., pp. 25-36, Springer Natural Hazards, Singapore (2017).

11. X. Li and S. Lehner, "Observation of sea surface wind and wave in X-band TerraSAR-X and TanDEM-X over Hurricane Sandy," Chapter 6 in Hurricane Monitoring with Space Borne Synthetic Aperture Radar, X. Li, Ed., pp. 99-118, Springer Natural Hazards, Singapore (2017).

12. F. T. Ulaby, R. K. Moore, and A. K. Fung, Microwave Remote Sensing: Radar Remote Sensing and Surface Scattering and Emission Theory, Volume II: Active and Passive, Addison-Wesley Publishers, Massachusetts (1982).

13. K. Hasselmann et al., "Theory of synthetic aperture radar ocean imaging: a MARSEN view," J. Geophys. Res. 90(3), 4659-4686 (1985).

14. K. Hasselmann and W. Alpers, "The response of synthetic aperture radar to ocean surface waves," in Wave Dynamics and Radio Probing of the Ocean Surface, O. M. Phillips and K. Hasselmann, Eds., pp. 393-402, Plenum Publishing Corporation, New York (1986).

15. R. K. Raney, "Radar fundamentals: technical perspective," Chapter 2 in Manual of Remote Sensing, Principles and Applications of Imaging Radar, F. M. Henderson and A. J. Lewis, Eds., 3rd ed., pp. 15-45, John Wiley and Sons, New York (1998).

16. J. Lewis, F. M. Henderson, and D. W. Holcomb, "Radar fundamentals: the geoscience perspective," Chapter 3 in Manual of Remote Sensing, Principles and Applications of Imaging Radar, F. M. Henderson and A. J. Lewis, Eds., 3rd ed., pp. 157-160, John Wiley and Sons, New York (1998).

17. B. Minchew, C. E. Jones, and B. Holt, "Polarimetric analysis of backscatter from the deepwater horizon oil spill using L-band synthetic aperture radar," IEEE Trans. Geosci. Remote Sens. 50(10), 3812-3830 (2012).

18. L. C. Smith, "Satellite remote sensing of river inundation area, stage, and discharge: a review," Hydrol. Process. 11, 1427-1439 (1997).

19. M. S. Horritt et al., "Waterline mapping in flooded vegetation from airborne SAR imagery," Remote Sens. Environ. 85, 271-281 (2003).

20. D. C. Mason et al., "Improving river flood extent delineation from synthetic aperture radar using airborne laser altimetry," IEEE Trans. Geosci. Remote Sens. 45(12), 3932-3943 (2007).

21. J. L. Foster and D. K. Hall, "Multisensor analysis of hydrologic features with emphasis on the Seasat SAR,” Photogramm. Eng. Remote Sens. 47(5), 655-664 (1981).

22. P. J. Moughinis-Mark, L. R. Gaddis, and C. Ferall, "The Mississippi river delta: the monitoring of coastal processes with spaceborne and airborne radar and multispectral experiments," in Proc. of the Int. Symp. on Remote Sensing of the Environment, Colorado, pp. 875-884 (1984).

23. E. Malnes, T. Guneriussen, and K. A. Høgda, "Mapping of flood-area by RADARSAT in Vansjø, Norway," in Proc. of the 29th Int. Symp. on Remote Sensing of the Environment, Buenos Aires, Argentina, 2002, https://www.researchgate.net/publication/240624565_ Mapping_of_floodarea_by_Radarsat_in_Vansjo_Norway (14 January 2017).

24. S. Solbø and I. Solheim, "Towards operational flood mapping with satellite SAR," in Proc. of the Envisat and ERS Symp. (ESA SP-572), H. Lacoste and L. Ouwehand, Eds., Salzburg, Austria, 2004, http://adsabs.harvard.edu/full/2005ESASP.572E.264S (4 February 2017).

25. F. M. Henderson, "Consistency of open surface detection with L-band SEASAT SAR imagery and confusion with other hydrologic features," in Proc. of the 13th Annual Conf. of Remote Sensing Society, pp. 69-78, University of Nottingham, Nottingham, United Kingdom (1987).

26. M. Danklmayer and M. Chandra, "Comparison of precipitation effects in space-borne Xand Ka-band SAR imaging," in Proc. of IEEE Geoscience and Remote Sensing Symp. (IGARSS), Vol. 4, pp. 909-912, University of Cape Town, Cape Town, South Africa (2009). 
Manavalan: Review of synthetic aperture radar frequency, polarization, and incidence angle...

27. M. Danklmayer and M. Chandra, "Precipitation effects for X- and Ka-band SAR," in European Conf. on Synthetic Aperture Radar (EUSAR), pp. 1-4, Eurogress, Aachen, Germany (2010).

28. T. L. Evans et al., "Using ALOS/PALSAR and RADARSAT-2 to map land cover and seasonal inundation in the Brazilian Pantanal," IEEE J. Sel. Top. Appl. Earth Obs. Remote Sens. 3(4), 560-575 (2010).

29. R. Manavalan, Y. S. Rao, and B. K. Mohan, "Comparative flood area analysis of C-band VH, VV, and L-band HH polarizations SAR data," Int. J. Remote Sens. 38(16), 4645-4654 (2017).

30. J. P. Ormsby, B. J. Blanchard, and A. J. Blanchard, "Detection of lowland flooding using active microwave systems," Photogramm. Eng. Remote Sens. 51(3), 317-328 (1985).

31. J. A. Richards, P. W. Woodgate, and A. K. Skidmore, "An explanation of enhanced radar backscattering from flooded forest," Int. J. Remote Sens. 8(7), 1093-1100 (1987).

32. L. L. Hess, J. M. Melack, and D. S. Simonett, "Radar detection of flooding beneath the forest canopy: a review," Int. J. Remote Sens. 11(7), 1313-1325 (1990).

33. L. L. Hess and J. M. Melack, "Mapping wetland hydrology and vegetation with synthetic aperture radar," Int. J. Ecol. Environ. Sci. 20, 197-205 (1994).

34. L. L. Hess et al., "Dual season mapping of wetland inundation and vegetation for the central Amazon basin," Remote Sens. Environ. 87, 404-428 (2003).

35. L. L. Hess and J. M. Melack, "Remote sensing of vegetation and flooding on Magela Creek floodplain (Northern Territory, Australia) with the SIR-C synthetic aperture radar," Hydrobiologia 500, 65-82 (2003).

36. S. I. Solomon, "Methodological considerations for the use of ERS-1 SAR imagery for the delineation of river networks in tropical forest areas," in Proc. of the First ERS-1 Symp. (SP359), ESA/ESRIN, Frascati, Italy, pp. 595-600 (1993).

37. Y. Wang et al., "Understanding the radar backscattering from flooded and non-flooded Amazonian forests: results from canopy backscatter modeling," Remote Sens. Environ. 54(3), 324-332 (1995).

38. F. M. Henderson, "Environmental factors and the detection of open surface water using X-band radar imagery," Int. J. Remote Sens. 16(13), 2423-2437 (1995).

39. E. S. Kasischke and L. L. Bourgeau-Chavez, "Monitoring south Florida wetlands using ERS-1 SAR imagery," Photogramm. Eng. Remote Sens. 33, 281-291 (1997).

40. P. A. Townsend and S. J. Walsh, "Modelling floodplain inundation using integrated GIS with radar and optical remote sensing," Geomorphology 21(3-4), 295-312 (1998).

41. R. M. Rao et al., "Monitoring the spatial extent of coastal wetlands using ERS-1 SAR data," Int. J. Remote Sens. 20(13), 2509-2517 (1999).

42. E. Alsdorf et al., "Interferometric radar measurements of water level changes on the Amazon floodplain," Nature 404, 174-177 (2000).

43. P. A. Townsend, "Mapping seasonal flooding in forested wetlands using multi-temporal Radarsat SAR," Photogramm. Eng. Remote Sens. 67(7), 857-864 (2001).

44. P. A. Townsend, "Estimating forest structure in wetlands using multitemporal SAR," Remote Sens. Environ. 79(2-3), 288-304 (2002).

45. P. A. Townsend and J. R. Foster, "Assessing flooding and vegetation structure in forested wetlands using Radarsat SAR imagery," in IEEE Int. Geoscience and Remote Sensing Symp. (IGARSS), Toronto, Canada, Vol. 2, pp. 1171-1173 (2002).

46. M. P. F. Costa, "Use of SAR satellites for mapping zonation of vegetation communities in the Amazon floodplain," Int. J. Remote Sens. 25(10), 1817-1835 (2004).

47. M. W. Lang, P. A. Townsend, and E. S. Kasischke, "Influence of incidence angle on detecting flooded forests using C-HH synthetic aperture radar data," Remote Sens. Environ. 112, 3898-3907 (2008).

48. S. H. Hong, S. Wdowinski, and S. W. Kim, "Evaluation of TerraSAR-X observations for wetland InSAR application," IEEE Trans. Geosci. Remote Sens. 48(2), 864-873 (2010).

49. K. Voormansik et al., "Flood mapping with TerraSAR-X in forested regions in Estonia," IEEE J. Sel. Top. Appl. Earth Obs. Remote Sens. 7(2), 562-577 (2014).

50. K. O. Pope, J. M. Rey-Benayas, and J. F. Paris, "Radar remote sensing of forest and wetland ecosystems in the Central American tropics," Remote Sens. Environ. 48, 205-219 (1994). 
Manavalan: Review of synthetic aperture radar frequency, polarization, and incidence angle...

51. S. S. Saatchi et al., "Mapping land cover types in the Amazon Basin using $1 \mathrm{~km}$ JERS-1 mosaic," Int. J. Remote Sens. 21(6-7), 1201-1234 (2000).

52. A. Giacomelli, M. Mancini, and R. Rosso, "Assessment of flooded areas from ERS-1 PRI data, an application to the 1994 flood in Northern Italy," Phys. Chem. Earth. 20(5-6), 469474 (1995).

53. R. Oberstadler, H. H. Nsch, and D. Huth, "Assessment of the mapping capabilities of ERS-1 SAR data for flood mapping: a case study in Germany," Hydrol. Process. 11, 1415-1425 (1997).

54. D. C. Mason et al., "Flood detection in urban areas using TerraSAR-X," IEEE Trans. Geosci. Remote Sens. 48(2), 882-894 (2010).

55. D. C. Mason et al., "Near real-time flood detection in urban and rural areas using highresolution synthetic aperture radar images," IEEE Trans. Geosci. Remote Sens. 50(8), 3041-3052 (2012).

56. D. C. Mason et al., "Automatic near real-time selection of flood water levels from highresolution synthetic aperture radar images for assimilation into hydraulic models: a case study," Remote Sens. Environ. 124, 705-716 (2012).

57. D. C. Mason et al., "Detection of flooded urban areas in high resolution synthetic aperture radar images using double scattering," Int. J. Appl. Earth Obs. Geoinf. 28, 150-159 (2014).

58. G. Franceshetti, A. Iodice, and D. Riccio, "A canonical problem in electromagnetic backscattering from buildings," IEEE Trans. Geosci. Remote Sens. 40(8), 1787-1801 (2002).

59. L. Giustarini et al., "Change detection approach to flood mapping in urban areas using TerraSAR-X," IEEE Trans. Geosci. Remote Sens. 51(4), 2417-2430 (2013).

60. B. Pradhan, M. S. Tehrany, and M. N. Jebur, "A new semiautomated detection mapping of flood extent from TerraSAR-X satellite image using rule-based classification and Taguchi optimization techniques," IEEE Trans. Geosci. Remote Sens. 54(7), 4331-4342 (2016).

61. L. L. Hess et al., "Delineation of inundated areas and vegetation along the Amazon floodplain with SIR-C synthetic aperture radar," IEEE Trans. Geosci. Remote Sens. 33(4), 896904 (1995).

62. J. B. Henry et al., "ENVISAT multi-polarised ASAR data for flood mapping," in IEEE Int. Geoscience and Remote Sensing Symp. (IGARSS), Melbourne, Australia, Vol. 2, pp. 11361138 (2003).

63. J. B. Henry et al., "ENVISAT multi-polarised ASAR data for flood mapping," Int. J. Remote Sens. 27(10), 1921-1929 (2006).

64. D. G. Leckie and K. J. Ranson, "Forestry applications using imaging radar," Chapter 9 in Manual of Remote Sensing, Principles and Applications of Imaging Radar, F. M. Henderson and A. J. Lewis, Eds., pp. 435-495, 3rd ed., John Wiley and Sons, New York (1998).

65. D. C. Evans et al., "Multipolarization radar images for geologic mapping and vegetation discrimination," IEEE Trans. Geosci. Remote Sens. GE-24(2), 246-257 (1986).

66. S. T. Wu and S. A. Sader, "Multipolarization SAR data for surface feature delineation and forest vegetation characterization," IEEE Trans. Geosci. Remote Sens. GE-25(1), 67-76 (1987).

67. S. T. Wu, "Analysis of synthetic aperture radar data acquired over a variety of land cover," IEEE Trans. Geosci. Remote Sens. GE-22(6), 550-557 (1984).

68. G. Schumann et al., "High-resolution 3-D flood information from radar imagery for flood hazard management," IEEE Trans. Geosci. Remote Sens. 45(6), 1715-1725 (2007).

69. S. V. Nghiem et al., "Flood mapping over the Asian continent during the 1999 summer monsoon season," in Proc. of the IEEE Int. Geoscience and Remote Sensing Symp., Honolulu, Hawaii, pp. 2027-2028 (2000).

70. R. Manavalan and Y. S. Rao, "DEM and SAR image based flood feature extraction techniques to map the deep and shallow flood inundated regions of known as well as remote disaster regions," Geocarto Int. 29(7), 745-757 (2014).

71. M. Imhoff et al., "Forest canopy characterization and vegetation penetration assessment with space-borne radar," IEEE Trans. Geosci. Remote Sens. GE-24(4), 535-542 (1986).

72. Y. Wang and M. L. Imhoff, "Simulated and observed L-band HH radar backscatter from tropical mangrove forests," Int. J. Remote Sens. 14(15), 2819-2828 (1993). 
Manavalan: Review of synthetic aperture radar frequency, polarization, and incidence angle...

73. L. L. Bourgeau-Chavez et al., "Analysis of space-borne SAR data for wetland mapping in Virginia riparian ecosystems," Int. J. Remote Sens. 22(18), 3665-3687 (2001).

74. J. Sokol, H. NcNairn, and T. J. Pultz, "Case studies demonstrating the hydrological applications of C-band multi-polarized and polarimetric SAR," Can. J. Remote Sens. 30(3), 470483 (2004).

75. J. Li, W. Chen, and R. Touzi, "Optimum RADARSAT-1 configurations for wetlands discrimination: a case study of the Mer Bleue peat bog," Can. J. Remote Sens. 33(S1), S46-S55 (2007).

Ramanuja Manavalan has nearly two decades of work experience in the fields of remote sensing applications specialized to HPC-based disaster management models. Currently, he works at the Center for Development of Advanced Computing, Bangalore, India. He has completed his doctoral thesis in SAR image analysis techniques for flood area mapping from IIT, Bombay, India, as well as completed a MTech degree in remote sensing, MBA degree in operation research, and MSc degree in geology. 